\title{
High Efficiency of Natural Safiot Clay to Remove Industrial Dyes from Aqueous Media: Kinetic, Isotherm Adsorption and Thermodynamic Studies
}

\author{
Aziz El Kassimi ${ }^{1}$ * ${ }^{\mathbb{D}}$, Youness Achour ${ }^{1}$, Mamoune El Himri ${ }^{1}$, My Rachid Laamari ${ }^{1}$, Mohammadine El \\ Haddad 1, * (D) \\ 1 Laboratory of Analytical and Molecular Chemistry, Poly-disciplinary Faculty of Safi, Cadi Ayyad University, BP 4162, \\ 46000 Safi, Morocco \\ * Correspondence: azizelkassimi2012@gmail.com (A.E.K.); elhaddad71@gmail.com (M.E.H.);
}

Scopus Author ID 57191952633

Received: 18.12.2020; Revised: 16.01.2021; Accepted: 21.01.2021; Published: 31.01.2021

\begin{abstract}
This study's objective was to demonstrate the potential of Natural Safiot Clay (NSC) for removing cationic dyes $\mathrm{MB}$ and Safranin from synthetic wastewater. The operation parameters investigated included initial concentrations, adsorbent dose, initial pH, and temperature. Experimental tests were conducted in a batch process. The experimental isotherms data were analyzed using Langmuir, Freundlich, and Dubinin-Radushkevich isotherm models. The Langmuir model obtained the best fit with a maximum monolayer adsorption capacity of $68.49 \mathrm{mg} / \mathrm{g}$ for $\mathrm{MB}$ and $45.45 \mathrm{mg} / \mathrm{g}$ for safranin. Pseudo-first-order, pseudo-second-order kinetic equations, and intraparticle diffusion models were used to examine the experimental data at different initial concentrations. It was found that the pseudo-second-order kinetic model described the data of dyes adsorption on NSC adsorbent very well. Thermodynamic adsorption processes were found to be spontaneous, exothermic, and physical reactions. The natural safiot clay was characterized using the following technique: DRX, XRF, SEM, EDX, and FT-IR.
\end{abstract}

Keywords: adsorption; dyes; natural safiot clay; isotherms; kinetics; thermodynamic; characterization.

(C) 2021 by the authors. This article is an open-access article distributed under the terms and conditions of the Creative Commons Attribution (CC BY) license (https://creativecommons.org/licenses/by/4.0/).

\section{Introduction}

The growth of humanity and the development of science and technology are causing an environmental disorder due to the pollution of water by a number of pollutants, including synthetic dyes, which have a complex molecular structure that makes them more stable and difficult. These dyes are discharged with the liquid effluents, which are most of the time directly discharged into watercourses without prior treatment [1].

These colored wastes pose a great threat to human health and the environment because many of the dyes are toxic. Traditional processes such as biological processes give unsatisfactory results due to the composition of these releases of toxic and dyestuffs, which are difficult to biodegrade; on the other hand, physicochemical processes, which include coagulation-flocculation, oxidation, and membrane filtration, have been widely studied and have revealed a high efficiency in water discoloration [2,3]. These techniques have proven to be very effective. However, their high cost has prompted many researchers to try other cheaper and abundant materials. The elimination of dyes in aqueous solutions by adsorption on different solid materials, particularly on activated carbon, has been the subject of much work [4-7]. 
The adsorption of dyes on activated carbon has been found to be very effective, but its use remains limited due to the difficulties of its regeneration and its high cost [8]. For this reason, new materials have been the subject of much research in recent years. From this perspective, using clay as an adsorbent is of great interest because of its effectiveness, accessible cost, and abundance. A lot of research has been done on clays, and all have shown their depollution efficiency towards dyes $[9,10]$. The importance given to these materials is granted to their abundant availability in nature and their great capacity to retain various pollutants, which is offered by their structure in sheets, which gives a large specific surface towards the adsorption $[11,12]$.

Our choice focused on clay, an adsorbent material found in abundance in Morocco, effective and more economical. The use of clays for the depollution of waters contaminated by dyes requires a good knowledge of their mineralogical characteristics and the mechanism of eliminating these pollutants. The purpose of this study was to demonstrate the ability of Natural Safiot Clay in the removal of industrial dyes. An extensive study of dyes removal includes:

- Optimization of the conditions for maximum adsorption by studying the effect of different parameters such as initial concentration, adsorbent dose, initial $\mathrm{pH}$ and temperature on the removal of dye from aqueous solutions.

- The determination of the adsorption capacity of natural safiot clay was studied using the adsorption isotherms. Kinetic and Thermodynamic studies were also carried out.

\section{Materials and Methods}

For this study, we have chosen methylene blue (MB) and safranin (SAF) as representative cationic dyes that were purchased from Sigma Aldrich and were of analytical grade. The chemical structures of the studied dyes are given in Figure 1. Stock solutions of dyes were prepared by dissolving them in distilled water. Dyes concentrations for experiments adsorption were prepared by successive dilution of the pre-made stock solutions. $\lambda_{\max }$ (wavelength at which maximum absorption occurs) of MB and SAF dyes are $663 \mathrm{~nm}$ and 520 nm (Figure 2).
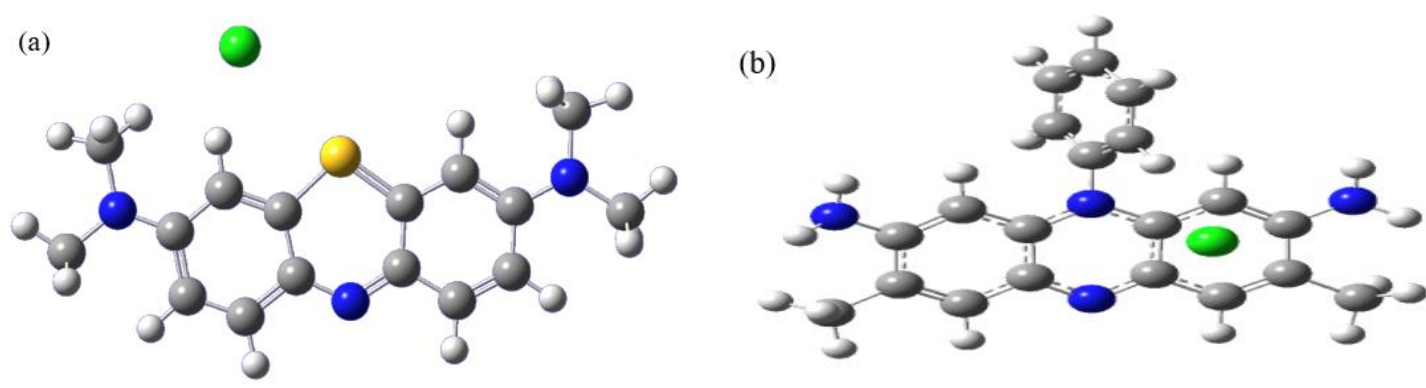

Figure 1. Chemical structures of methylene blue (a) and safranin (b).

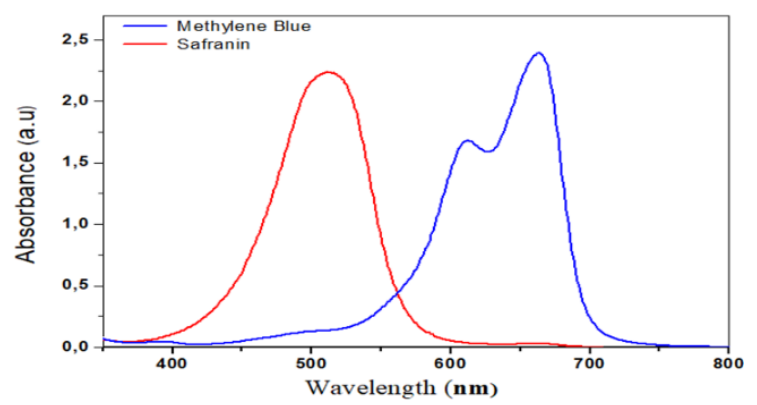

Figure 2. Experimental UV/vis absorption spectra for methylene blue and safranin. 
The natural safiot clay abbreviated as (NSC) used in this study were of Moroccan sources. The NSC adsorbent was rinsed with distilled water to ensure the removal of dust and any soluble impurities that may exist. Then it was kept at room temperature and exposed to air for natural drying. The sample was then placed in the oven at $105^{\circ} \mathrm{C}$ overnight to remove moisture and any volatile impurities that may exist. The dried clay was washed several times repeatedly with distilled water until the water becomes almost colorless. The treatment clay dried again in an oven at $105^{\circ} \mathrm{C}$ overnight and stored later in desiccators to prevent moisture and is ready for experimental use.

Chemical composition, surface morphology, and the nature of functional groups responsible for adsorption for dye onto the NSC adsorbent were studied by X-Ray Diffraction (XRD), X-ray fluorescence (XRF), Energy Dispersive X-ray spectroscopy (EDX), Scanning Electron Microscopy (SEM) and Fourier Transform Infrared (FT-IR).

Batch adsorption experiments were conducted to investigate the influence of physicochemical parameters such as adsorbent dose (5-35 mg), initial dye concentration (20$40 \mathrm{mg} / \mathrm{L}), \mathrm{pH}(2-12)$, and temperature $\left(25^{\circ} \mathrm{C}-35^{\circ} \mathrm{C}\right)$ on dye adsorption. The working solutions' $\mathrm{pH}$ was adjusted to the desired values with dilute $\mathrm{HCl}(0.1 \mathrm{M})$ or $\mathrm{NaOH}(0.1 \mathrm{M})$ using a pHMeter HANNA 5222. After stirring a prescribed contact time, the solution was filtrated using a filter syringe. The concentration was measured using UV/Visible spectrophotometer (Janway 6300). For the qualification of the removal dye onto NSC adsorbent, two manners may give:

- The \% removal of dye expressed as follows:

$$
\% \text { Removal dye }=\frac{C_{0}-C_{e}}{C_{0}} * 100
$$

- Adsorption capacity at equilibrium, qe $(\mathrm{mg} / \mathrm{g})$ calculated using the equation:

$$
q_{e}(m g / g)=\frac{C_{0}-C_{e}}{W} * V
$$

These relationships depend on the type of adsorption that occurs. Where $\mathrm{C}_{0}$ and $\mathrm{C}_{\mathrm{e}}$ are the initial and equilibrium dye concentrations in aqueous solution $(\mathrm{mg} / \mathrm{L})$, respectively, $\mathrm{V}$ is the volume of aqueous solution $(\mathrm{L})$, and $\mathrm{W}$ is a dry weight adsorbent $(\mathrm{g})$.

\section{Results and Discussion}

\subsection{Characterization of natural Safiot clay adsorbent.}

\subsubsection{XRD analysis.}

X-ray diffraction analysis allows us to identify the different mineralogical phases contained in our material.

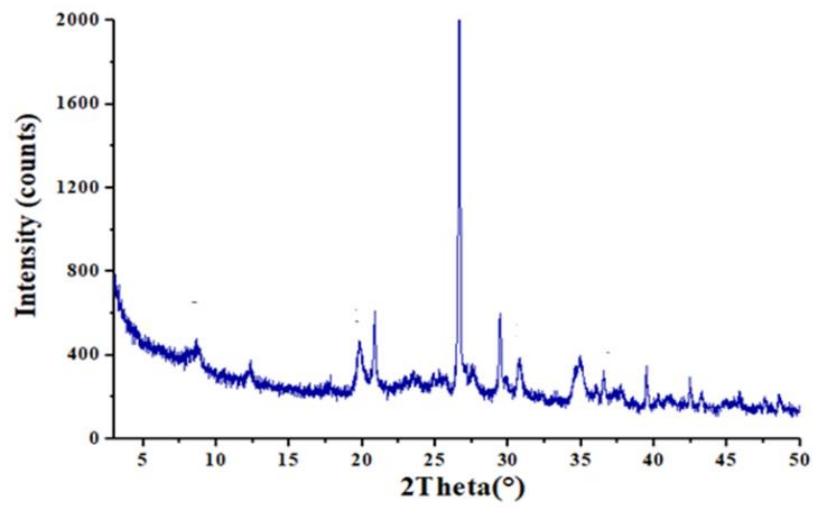

Figure 3. X-ray diffraction of natural safiot clay. 
The X-ray diffraction patterns of NSC adsorbent are illustrated in Figure 3. This result demonstrated the principal presence of kaolinite characterized by an intense peak at $2 \theta=26.63^{\circ}$ and a series of peaks with varying intensities at $12.33^{\circ}, 19.75^{\circ}, 40.85^{\circ}$ and those of quartz at $20.87^{\circ} .37 .92^{\circ}$ and 42.440 . Also, the reflections spectrum at $2 \theta=8.62^{\circ}, 29.47^{\circ}$, and $30.81^{\circ}$ confirm the presence of illite, calcite, and dolomite, respectively. We see that the diagram also shows the presence of the peak corresponds to the following minerals: Kaolinite, calcite, and vermiculite, which implies that our clay is heterogeneous.

\subsubsection{XRF analysis.}

Analysis of the chemical composition by X-ray fluorescence allowed us to determine clay constituents in oxides whose contents are evaluated in mass percentages. Table 1 shows the results of the analysis of the chemical composition of natural safiot clay. Based on these results, it can be seen that silica and alumina are predominant constituents with a very large percentage. This indicates that the material is part of kaolinite from a group of clay minerals. Moreover, relatively high calcium indicates that our material is rich in calcite $\left(\mathrm{CaCO}_{3}\right)$. The other oxides $\left(\mathrm{Fe}_{2} \mathrm{O}_{3}, \mathrm{MgO}, \mathrm{K}_{2} \mathrm{O}\right.$, and $\left.\mathrm{Na}_{2} \mathrm{O}\right)$ reaches a percentage varying from 7.63 to 13.9, which shows that our clay is not pure [13]. In addition, the high content of these oxides compared to the contents of other oxides probably shows that the clay contains exchangeable cations such as $\mathrm{Mg}^{2+}, \mathrm{K}^{+}$, or $\mathrm{Na}^{+}$.

Table 1. X-ray fluorescence analysis of oxide content (\%) for the clay sample.

\begin{tabular}{l|l|l|l|l|l|l|l|l|l|l|l|l} 
Component & $\mathbf{S i O}_{2}$ & $\mathbf{A l}_{2} \mathbf{O}_{3}$ & $\mathbf{F e}_{2} \mathbf{O}_{3}$ & $\mathbf{C a O}$ & $\mathbf{K}_{\mathbf{2}} \mathbf{O}$ & $\mathbf{M g O}$ & $\mathbf{T i O}_{2}$ & $\mathbf{N a}_{2} \mathbf{O}$ & $\mathbf{S O}_{3}$ & $\mathbf{P}_{2} \mathbf{O}_{5}$ & $\mathbf{M n O}$ & $\mathbf{L O I}^{\mathbf{a}}$ \\
\hline Weight $(\%)$ & 47.44 & 31.24 & 6.18 & 4.99 & 4.63 & 2.54 & 1.02 & 0.52 & 0.18 & 0.15 & 0.03 & 13.67
\end{tabular}

${ }^{a}$ Loss on ignition: volatile components, water, organic matter, $\mathrm{CO}_{2}$, etc.

\subsubsection{SEM-EDX analysis.}

Analysis by scanning electron microscopy was carried out to observe the morphology, structure, and distribution of the grains of our adsorbent material studied. The scanning electron microscope image (Figure 4) shows aggregates of kaolin grains in a spherical form and heterogeneous size, the interstices between the grains form pores. We also observe large irregularly shaped cavities; this confirms our clay's heterogeneous composition revealed by the XRD (kaolinite + calcite + vermiculite).

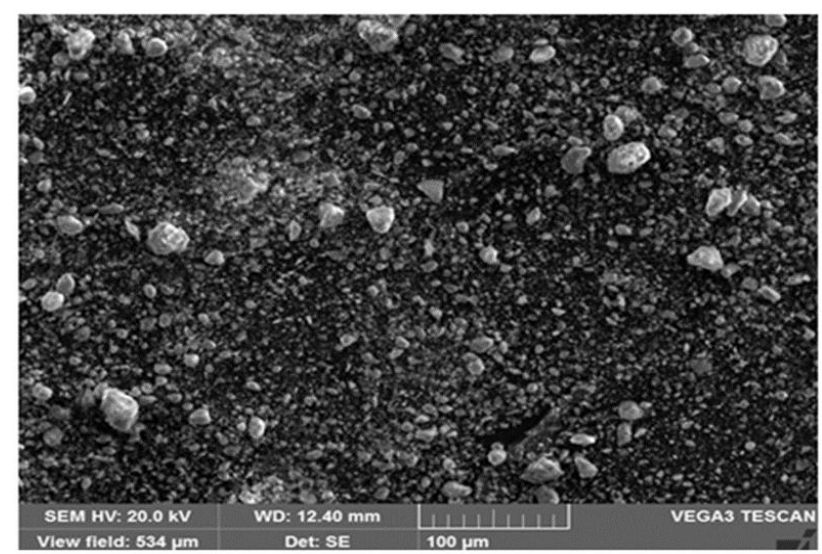

Figure 4. SEM micrograph of the Natural Safi Clay. 
In order to achieve an accurate characterization of NSC adsorbent, we have used the EDX spectrum. Table 2 depicts the atomic composition of NSC adsorbent. So, the request adsorbent showed a high percentage of silica, alumina, and oxygen, which are characteristic of alumino-silicates. Other elements are present in trace amounts ( $\mathrm{Fe}, \mathrm{Ti}, \mathrm{Mg}, \mathrm{Na}, \mathrm{K}$, and $\mathrm{Ca}$ ). Figure 5 depicts the EDX spectrum of NSC adsorbent. In this fact, the intense peaks for Si and $\mathrm{Al}$ elements could be ascribed to clay minerals and possibly free $\mathrm{SiO}_{2}$ (vide infra) and $\mathrm{Al}_{2} \mathrm{O}_{3}$, whereas Ti probably results from anatase or rutile impurities. Furthermore, elements such as $\mathrm{C}, \mathrm{Ca}$, and $\mathrm{Mg}$ are likely to be due to carbonates such as dolomite $\left(\mathrm{CaMg}\left(\mathrm{CO}_{3}\right)_{2}\right)$ and/or calcite $\left(\mathrm{CaCO}_{3}\right)$, as evidenced by XRD.

Table 2. Atomic and mass percentage of the natural Safiot clay constituents.

\begin{tabular}{l|c|c|c|c|c|c|c|c|c|c} 
Elements & $\mathbf{O}$ & $\mathbf{C}$ & $\mathbf{N a}$ & $\mathbf{M g}$ & $\mathbf{A l}$ & $\mathbf{S i}$ & $\mathbf{K}$ & $\mathbf{C a}$ & $\mathbf{T i}$ & $\mathbf{F e}$ \\
\hline \% Atomic & 57.87 & 12.96 & 0.59 & 1.25 & 7.50 & 13.78 & 2.18 & 1.70 & 0.19 & 1.72 \\
\hline \% Mass & 46.70 & 7.85 & 0.68 & 1.53 & 10.20 & 19.52 & 4.30 & 3.43 & 0.47 & 4.85
\end{tabular}

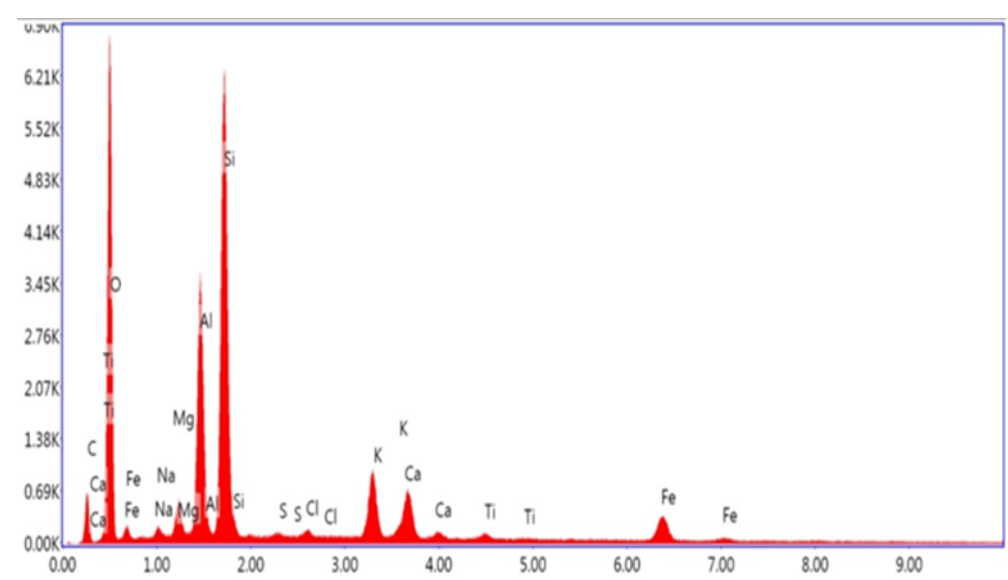

Figure 5. EDX Spectrum of natural Safiot clay.

\subsubsection{FTIR analysis.}

Fourier transform infrared (FTIR) analysis was applied to determine the functional groups present on the surface of natural Safiot clay and understand its adsorption mechanism. The infrared spectra were recorded from 400 to $4000 \mathrm{~cm}^{-1}$ is shown in Figure 6 . The absorption bands that appear in the region from $3700 \mathrm{~cm}^{-1}$ to $3600 \mathrm{~cm}^{-1}$ correspond to the stretching vibrations of the structural hydroxyl groups characteristic of kaolinite. The band stretching between $1700 \mathrm{~cm}^{-1}$ and $1600 \mathrm{~cm}^{-1}$ can be attributed to the $\mathrm{OH}$ group's valence vibrations of the water adsorbed between the sheets [14]. At the same time, the characteristic bands of carbonates were detected at $1430 \mathrm{~cm}^{-1}$ and $2922 \mathrm{~cm}^{-1}$ [15]. An intense band located between $1200 \mathrm{~cm}^{-1}$ and $900 \mathrm{~cm}^{-1}$ and centered around $1030 \mathrm{~cm}^{-1}$ corresponds to the Si-O bond's valence vibrations (Quartz) [16]. The presence of a band between $908 \mathrm{~cm}^{-1}$ and $915 \mathrm{~cm}^{-1}$ may be due to the bending vibrations of the Al-Al-OH and Al-Mg-OH groups [14]. The bands between 787 $\mathrm{cm}^{-1}$ and $748 \mathrm{~cm}^{-1}$ are attributable to the vibrations of elongation of the Si-O-Al bonds (Kaolinite) and the hydroxyls perpendicular to the surface (translational $\mathrm{OH}$ ) [13]. The bands, which lie between $540 \mathrm{~cm}^{-1}$ and $516 \mathrm{~cm}^{-1}$, are attributed to the deformation of $\mathrm{Si}-\mathrm{O}-\mathrm{Al}{ }^{\mathrm{VI}}$ (VI corresponds to the octahedral position). However, the absorption bands at 423, 480, 534, and $694 \mathrm{~cm}^{-1}$ correspond to quartz [17]. 


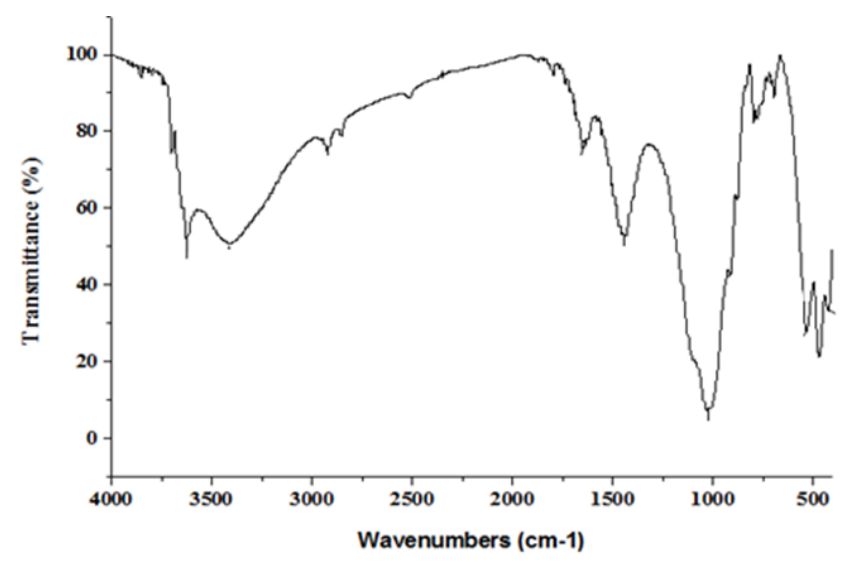

Figure 6. FT-IR spectrum of Natural Safiot Clay.

\subsection{Effect of adsorbent dose onto the \% removal dye.}

It's recognized that adsorbent dose is an important parameter influencing the sorption processes since it determines the adsorption capacity of an adsorbent for a given initial concentration of the adsorbate under the operating conditions. In our case, the effect of NSC adsorbent dose in the range of $5-35 \mathrm{mg}$ on the adsorption removal of the MB and SAF dyes. The behavior of the two systems MB-NSC and SAF-NSC is illustrated in Figure 7. Whatever the studied system MB-NSC or SAF-NSC and from the data given in Figure 7, MB or SAF Dye removal efficiency increased with increasing NSC adsorbent dose. The percentage removal increased from $49.16 \%$ to $97.03 \%$ for the MB-NSC system and varied from $13.14 \%$ to $94.35 \%$ for SAF-NSC system. Figure 6 also depicts the variation of adsorption capacity versus NSC adsorbent dose.

The MB dye uptake decreased from 98.34 to $27.72 \mathrm{mg} / \mathrm{g}$ and for SAF, dye decreased from 73.09 to $26.96 \mathrm{mg} / \mathrm{g}$ due to an increase in the adsorbent dose. This result can be attributed to the increase in the adsorbent surface area and the availability of more adsorption sites. Other researchers have reported similar results for the sorption of dyes by different biological materials $[18,19]$.

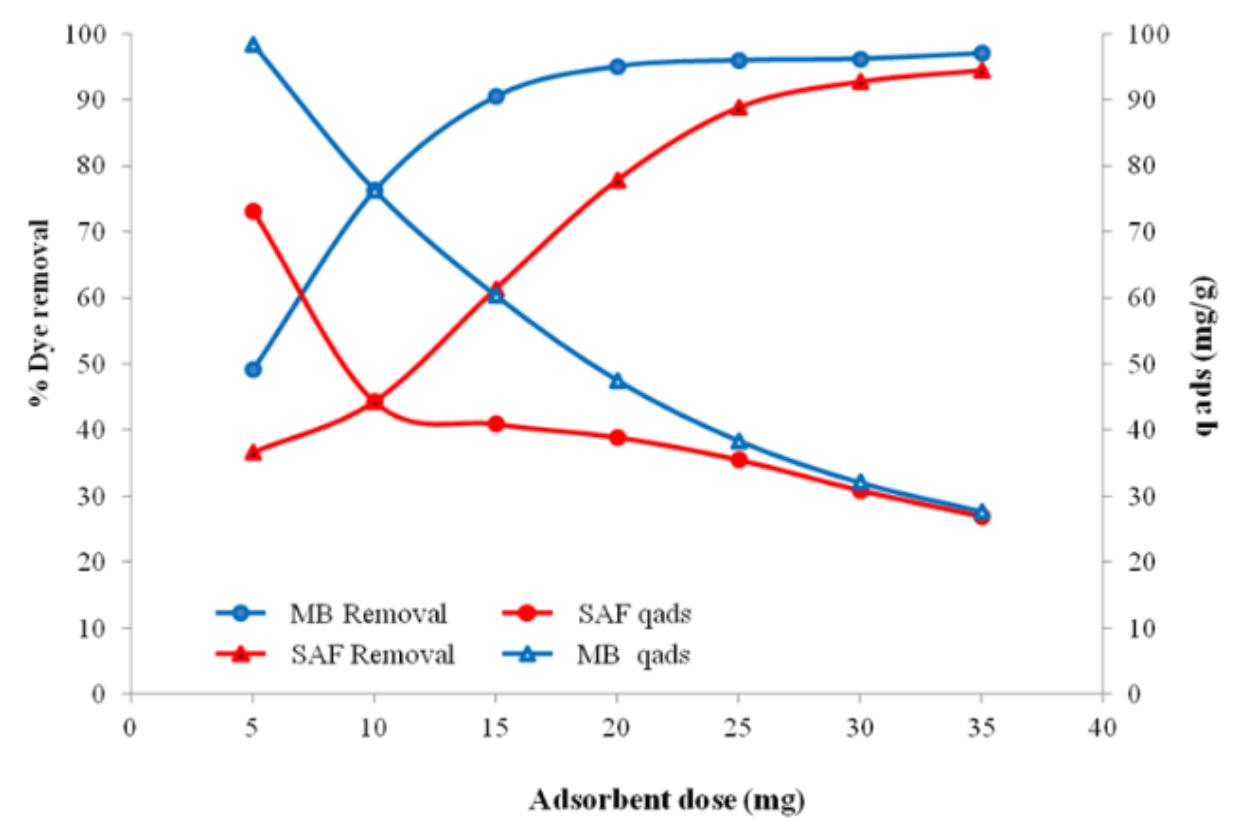

Figure 7. Effect of adsorbent amount on the \% adsorption of methylene blue (MB) and safranin (SAF). 


\subsection{Effect of initial dye concentration on the \% removal.}

The effect of initial concentrations of MB and SAF dyes was examined at five concentration levels $(20,25,30,35$, and $40 \mathrm{mg} / \mathrm{L})$ on the adsorption capacity and removal efficiency onto natural safiot clay was determined at $30 \mathrm{mg}$ of adsorbent dose and ambient temperature. The results regarding the effects of the initial concentration of dyes on NSC adsorbent's adsorption capacity are given in Figure 8. The dye uptake capacity increased from 32.06 to $58.45 \mathrm{mg} / \mathrm{g}$ for MB and 30.88 to $43.28 \mathrm{mg} / \mathrm{g}$ for SAF. In this case, the \% removal decreased from $96.21 \%$ to $87.67 \%$ and $92.66 \%$ to $64.92 \%$ for MB and SAF, respectively. These results indicated that NSC adsorbent adsorption sites for dyes adsorption were still unsaturated within the dye concentration range. In addition, increasing initial dye concentrations increase the number of collisions between dye ions and NSC adsorbent's surface area, which enhances the adsorption process.
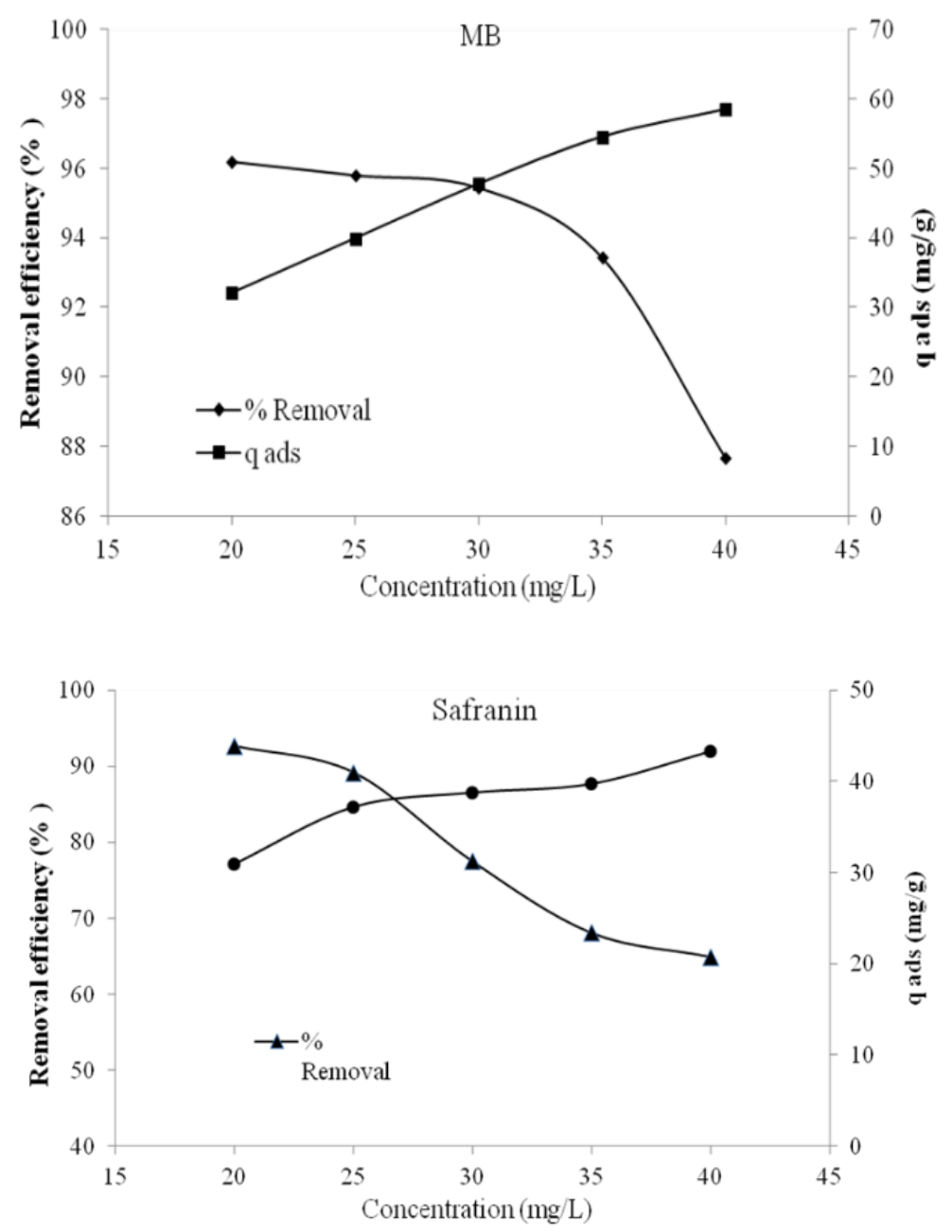

Figure 8. Effect of initial dye concentration on percentage removal and adsorption capacity.

\subsection{Effect of solution $\mathrm{pH}$.}

The initial $\mathrm{pH}$ of the aqueous solution is an important parameter controlling the adsorption process, where it affects both the degree of ionization of the dye and the adsorbent's surface properties. The solution $\mathrm{pH}$ effect was studied at the $\mathrm{pH}$ ranges of $2-12$, and the results are shown in Figure 9. The curves show that the percentage removal is most important for especially basic $\mathrm{pH}$ values below $\mathrm{pH} 12$. An increase in the $\mathrm{pH}$ from 2 to 12 increases the percentage of dye removal from the aqueous solution from $92 \%$ to $96 \%$ and $83 \%$ to $91 \%$ for 
$\mathrm{MB}$ and SAF. The pH Zero Point Charge (pHzPC) of NSC adsorbent was found to be 7.2 (Figure 10) and was determined using the $\mathrm{pH}$ drift method [20]. These results were explained by the fact that the negative charge dominates the adsorbent's surface in the basic medium. Thus, an electrostatic attraction exists between the negative charges of $\mathrm{OH}^{-}$deposited on the clay surface and the positive charges of the dyes.

Consequently, the mechanism proposed can be described in Eqs. 3 and 4.

$$
\begin{aligned}
& \mathrm{Si}-\mathrm{OH}+\mathrm{OH}^{-} \leftrightarrow \mathrm{Si}^{-} \mathrm{O}^{-}+\mathrm{H}_{2} \mathrm{O} \\
& \mathrm{Si}_{-} \mathrm{O}^{-}+\mathrm{MB}^{+} \text {or } \mathrm{SAF}^{+} \leftrightarrow \mathrm{Si}_{-}^{-\mathrm{O}^{-}} \mathrm{MB} \text { or } \mathrm{Si}-\mathrm{O}^{-+} \mathrm{SAF}
\end{aligned}
$$

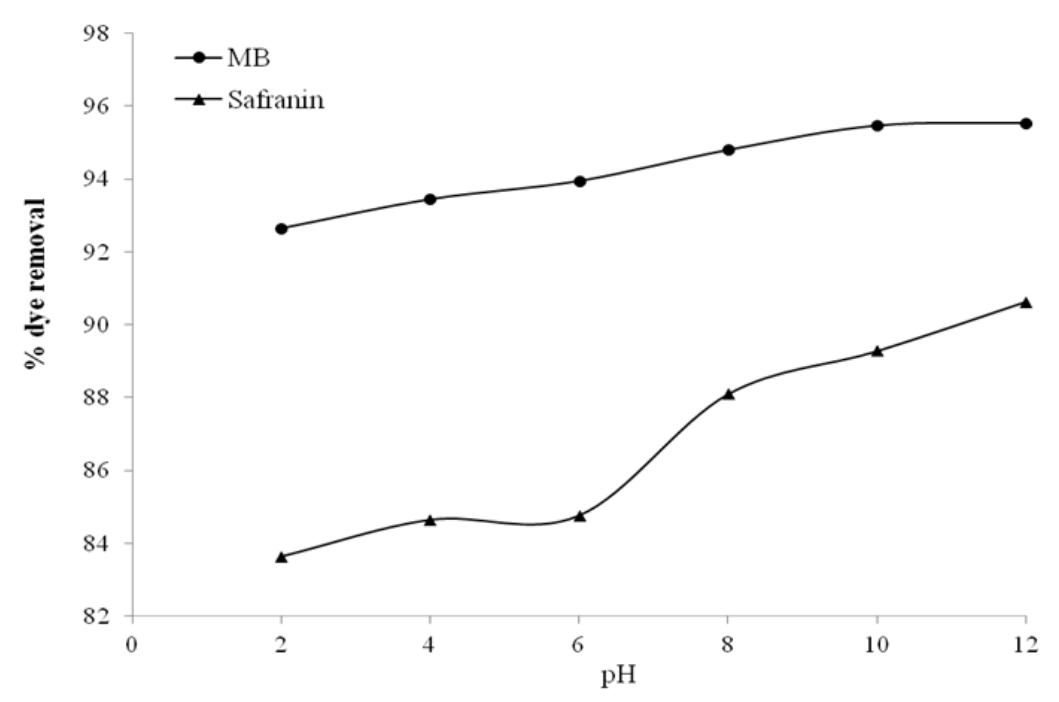

Figure 9. Effect of $\mathrm{pH}$ on the $\%$ adsorption of methylene blue and safranin.

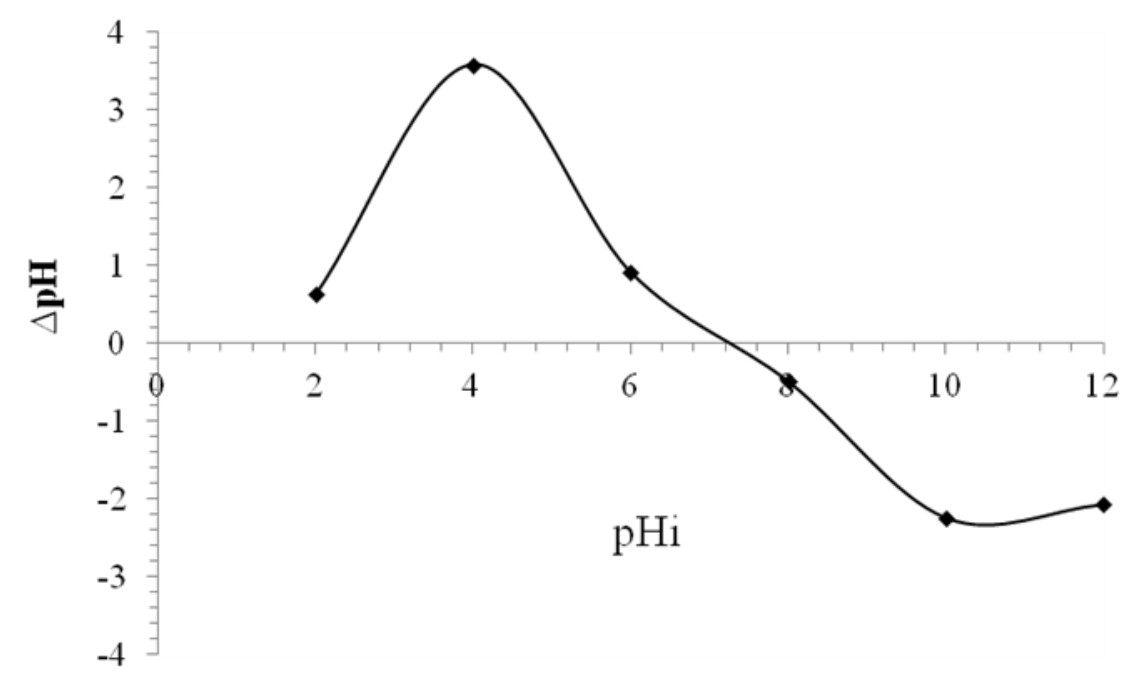

Figure 10.The pHzpc values for natural safiot clay.

\subsection{Effect of temperature.}

It is well known that temperature plays an important role in the adsorption process [21]. The influence of temperature on MB and Safranin's adsorption through NSC was determined in the range of $25^{\circ} \mathrm{C}-55^{\circ} \mathrm{C}$. It is clear from Figure 11. that with an increase in temperature of the solution from $25^{\circ} \mathrm{C}$ to $55^{\circ} \mathrm{C}$, the removal efficiency decreases from $93.68 \%$ to $90.63 \%$ for 
MB and from $92.38 \%$ to $82.46 \%$ for safranin. This result indicates that the process of adsorption is exothermic.

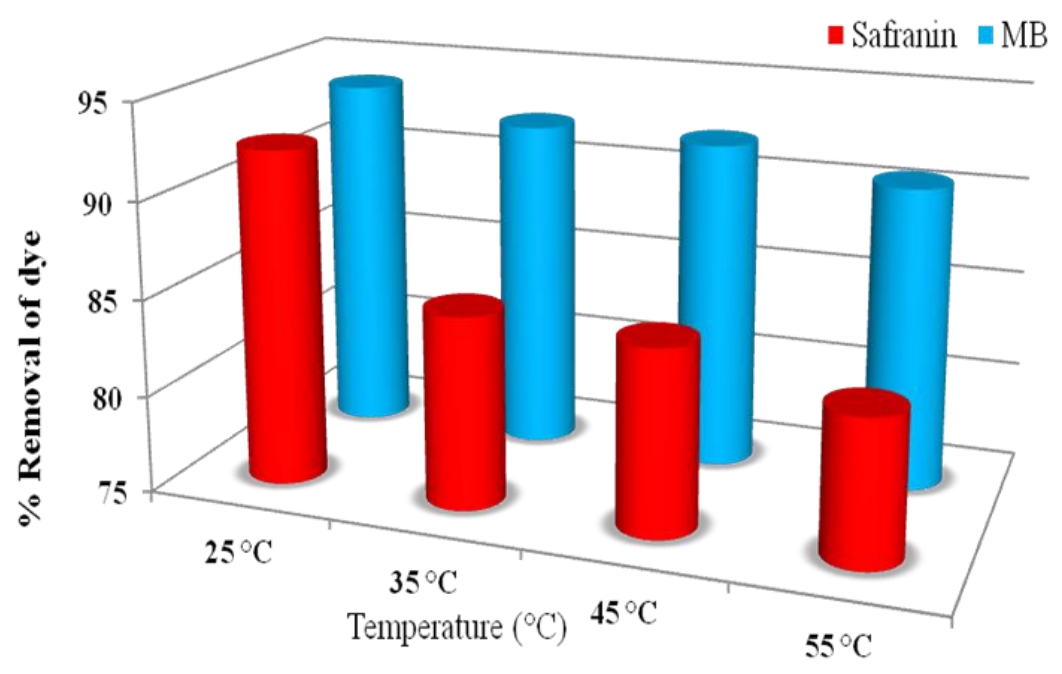

Figure 11. Plot Effect of temperature on the adsorption of MB and safranin.

\subsection{Adsorption isotherms.}

Adsorption isotherms play an important role in determining the maximum adsorption capacity and identifying the type of adsorption. The adsorption experiments' results were analyzed per the well-known models of Langmuir, Freundlich, and Dubinin-Radushkevich.

\subsubsection{Langmuir isotherm.}

The Langmuir isotherm is valid for monolayer adsorption on a homogenous surface, no interaction between adsorbate, and equivalent adsorption energies [22]. The linear isotherm equation is represented as:

$$
\frac{C_{e}}{q_{e}}=\frac{1}{q_{m} K_{L}}+\frac{1}{q_{m}} C_{e}
$$

Where $\mathrm{q}_{\mathrm{e}}$ is the amount of adsorbate uptake at equilibrium $\left(\mathrm{mg} \cdot \mathrm{g}^{-1}\right), \mathrm{K}_{\mathrm{L}}$ is the Langmuir constant, $\mathrm{q}_{\mathrm{m}}$ is the maximum quantity of adsorbate required to form a single monolayer on unit mass of adsorbent $(\mathrm{mg} / \mathrm{g})$, and $\mathrm{C}_{\mathrm{e}}$ is the equilibrium concentration of adsorbate in solution $(\mathrm{mg} / \mathrm{L})$. Further analysis of the Langmuir equation can be made using a dimensionless equilibrium parameter, the separation factor $R_{L}$ as given by the following equation [23]:

$$
R_{L}=\frac{1}{1+K_{L} C_{0}}
$$

Where $\mathrm{C}_{0}$ is the initial dye concentration. The value of separation factor $\mathrm{R}_{\mathrm{L}}$, indicates the nature of the adsorption process as given below: Irreversible $\left(R_{L}=0\right)$, favorable $\left(0<R_{L}<1\right)$, linear $\left(\mathrm{R}_{\mathrm{L}}=1\right)$ or unfavorable $\left(\mathrm{R}_{\mathrm{L}}>1\right)$.

\subsubsection{Freundlich isotherm.}

The Freundlich isotherm model is applicable for multilayer adsorption on a heterogeneous adsorbent surface with sites of different energies of adsorption [24]. The Freundlich isotherm model can be expressed as:

$$
\log \left(q_{e}\right)=\log \left(K_{f}\right)+\frac{1}{n} \log \left(C_{e}\right)
$$


Where $\mathrm{K}_{\mathrm{f}}(\mathrm{mg} / \mathrm{g})$ is the measurement of adsorption capacity and $1 / \mathrm{n}$ is the adsorption intensity of the adsorbent.

\subsubsection{Dubinin-Radushkevich (D-R) isotherm.}

The Dubinin-Radushkevich (D-R) model is a more generalized model as compared to the Langmuir isotherm. The model is based on the fact that there is no homogeneous surface or constant adsorption potential. The following equation indicates the D-R isotherm [25]:

$$
\begin{aligned}
& \ln \left(q_{e}\right)=\ln \left(q_{m}\right)-B \varepsilon^{2} \\
& \varepsilon=\text { RT } \operatorname{Ln}\left(1+\frac{1}{c_{\mathrm{e}}}\right)
\end{aligned}
$$

Where $\mathrm{q}_{\mathrm{m}}$ is the theoretical saturation capacity $(\mathrm{mg} / \mathrm{g}), \mathrm{B}$ is a constant related to the sorption energy $\left(\mathrm{mol}^{2} \mathrm{~kJ}^{-2}\right), \varepsilon$ is the Polanyi potential, $\mathrm{R}$ is the universal gas constant $(8.314 \mathrm{~J} / \mathrm{mol} . \mathrm{K})$, and $\mathrm{T}$ is the absolute temperature $(\mathrm{K})$. The mean free energy of adsorption $\mathrm{E}$ calculated from $\mathrm{B}$ using the following relation.

$$
\mathrm{E}=\frac{1}{\sqrt{2 \mathrm{~B}}}
$$

The Langmuir constants are given in Table 3. The calculated dimensionless separation factors, $\mathrm{R}_{\mathrm{L}}$ are 0.038 and 0.033 for $\mathrm{MB}$ and $\mathrm{SAF}$, respectively. This indicates favorable adsorption of MB and SAF dyes onto NSC adsorbent. $\mathrm{K}_{\mathrm{f}}$ and $1 / \mathrm{n}$ values can be calculated from the intercept and slope of the linear plot of $\log \left(\mathrm{q}_{\mathrm{e}}\right)$ versus $\log \left(\mathrm{C}_{\mathrm{e}}\right)$ are shown in Table 3 . The values of $1 / \mathrm{n}$ were found to lie between zero and one, indicating that MB and SAF dyes favorably adsorbed on NSC adsorbent.

The calculated D-R parameters for the adsorption of MB and SAF are given in Table 3. The magnitude of $\mathrm{E}(\mathrm{kJ} / \mathrm{mol})$ is used for estimating the type of adsorption mechanism. Suppose this value is between 8 and $16 \mathrm{~kJ} / \mathrm{mol}$. In that case, the adsorption process is controlled by a chemical mechanism. In contrast, for $\mathrm{E}<8 \mathrm{~kJ} / \mathrm{mol}$, the adsorption process proceeds through a physical mechanism. The calculated values of E (Table 3) suggested that dye's adsorption occurs via physical adsorption for two dyes.

A comparison of the isotherm constants along with regression coefficients $\left(R^{2}\right)$ is presented in Table 3. Comparing the Langmuir, Freundlich, and Dubinin-Radushkevich isotherms's regression coefficient values, it was demonstrated that the Langmuir isotherm was the most appropriate isotherm to describe the equilibrium data for dyes adsorption at the different studied concentrations. The maximum monolayer adsorption capacities were 68.49 and $45.45 \mathrm{mg} / \mathrm{g}$ for $\mathrm{MB}$ and safranin, respectively.

Table 3. Isotherm constants for methylene blue and safranin.

\begin{tabular}{l|l|l|l|l|l|l|l|l|l|l}
\multirow{2}{*}{ Dyes } & \multicolumn{9}{l}{ Langmuir } & \multicolumn{3}{l}{ Freundlich } & \multicolumn{3}{l}{ Dubinin-Radushkevich } \\
\cline { 2 - 12 } & $\mathbf{q m a x}_{\max }$ & $\mathbf{R}_{\mathbf{L}}$ & $\mathbf{R}^{\mathbf{2}}$ & $\mathbf{K}_{\mathbf{F}}$ & $\mathbf{1 / n}$ & $\mathbf{R}^{\mathbf{2}}$ & $\mathbf{q}$ max & $\mathbf{K}_{\text {D-R }}$ & $\mathbf{E}$ & $\mathbf{R}^{\mathbf{2}}$ \\
\hline MB & 68.49 & 0.038 & 0.992 & 37.89 & 0.314 & 0.852 & 59.03 & $110^{-7}$ & 2236 & 0.925 \\
\hline Safranin & 45.45 & 0.033 & 0.998 & 7.39 & 0.122 & 0.866 & 41.06 & $210^{-7}$ & 1581 & 0.912
\end{tabular}

\subsection{Adsorption kinetics.}

The kinetics of adsorption is an important characteristic in evaluating the efficiency of the adsorption process. Three kinetics models (pseudo-first order, pseudo-second-order, and intraparticle diffusion) were utilized to test the experimental data and predict the dye adsorption process's controlling mechanism. 


\subsubsection{Pseudo-first-order model.}

The linear form of the pseudo-first order is expressed as follows [26]:

$$
\log \left(q_{e}-q_{t}\right)=\log \left(q_{e}\right)-\frac{k_{1}}{2.303} t
$$

Where $\mathrm{q}_{\mathrm{e}}$ and $\mathrm{q}_{\mathrm{t}}(\mathrm{mg} / \mathrm{g})$ are the amount of adsorbate adsorbed at equilibrium and any time $\mathrm{t}$ (min), respectively, and $\mathrm{k}_{1}\left(\mathrm{~min}^{-1}\right)$ is the adsorption rate constant. The rate constant $\mathrm{k}_{1}$ and equilibrium adsorption capacities $\mathrm{q}_{\mathrm{e}}$ were obtained from the slope and intercept of the linear plots of $\log \left(\mathrm{q}_{\mathrm{e}}-\mathrm{q}_{\mathrm{t}}\right)$ against $\mathrm{t}$, respectively.

\subsubsection{Pseudo-second-order model.}

The pseudo-second-order model is given in equation [27]:

$$
\frac{t}{q_{t}}=\frac{1}{k_{2} q_{e}^{2}}+\frac{1}{q_{e}} t
$$

Where $\mathrm{k}_{2}$ is the rate constant of the pseudo-second-order model (g/mg.min), The rate constant $\mathrm{k}_{2}$ and $\mathrm{q}_{\mathrm{e}}$ can be calculated from the slope and intercept of the linear plots of $\mathrm{t} / \mathrm{q}_{\mathrm{t}}$ against $\mathrm{t}$, respectively.

\subsubsection{Intra particle diffusion model.}

The intra-particle diffusion equation [28] can be written as:

$$
\mathrm{q}_{\mathrm{t}}=\mathrm{k}_{\mathrm{id}} \mathrm{t}^{0.5}+\mathrm{c}
$$

Where $\mathrm{K}_{\mathrm{id}}$ is the intra-particle diffusion rate constant $\left(\mathrm{mg} / \mathrm{g} \cdot \mathrm{min}^{1 / 2}\right)$, and $\mathrm{C}$ is a constant that gives an idea about the thickness of the boundary layer $(\mathrm{mg} / \mathrm{g})$. A plot of $\mathrm{qt}_{\mathrm{t}} \mathrm{vs}$. $\mathrm{t}^{1 / 2}$ should be a straight line whose slope gives the value of the diffusion constant.

The lower values of $\mathrm{R}^{2}$ and the difference between the experimental and calculated equilibrium adsorption show that the pseudo-first-order and intraparticle diffusion model failed to describe the adsorption kinetics. The higher values of $\mathrm{R}^{2}>0.99$ and the good agreement between the experimental and calculated equilibrium adsorption for the pseudo-second-order model confirm that this one correctly describes the adsorption kinetics (see Table 4). The values of the rate constants $\left(\mathrm{k}_{2}\right)$ were found to decrease from 0.156 to $0.022 \mathrm{mg} / \mathrm{g}$.min and from 0.2 to $0.03 \mathrm{mg} / \mathrm{g}$.min as the initial concentration increased from 20 to $40 \mathrm{mg} / \mathrm{L}$, for $\mathrm{MB}$ and SAF,

\begin{tabular}{|c|c|c|c|c|c|c|c|c|c|c|c|}
\hline \multirow{2}{*}{\multicolumn{2}{|c|}{$\begin{array}{c}\text { Dyes Concentration } \\
(\mathrm{mg} / \mathrm{l})\end{array}$}} & & \multicolumn{3}{|c|}{ Pseudo-first order } & \multicolumn{3}{|c|}{ Pseudo-second order } & \multicolumn{3}{|c|}{ Intra particule diffusion } \\
\hline & & $\mathrm{q}_{\mathrm{e}}(\exp )$ & $\mathrm{qe}_{\mathrm{e}}(\mathrm{cal})$ & $\mathrm{K}_{1}$ & $\mathrm{R}^{2}$ & $\mathrm{qe}_{\mathrm{e}}(\mathrm{cal})$ & $\mathrm{K}_{2}$ & $\mathrm{R}^{2}$ & $\mathrm{Ki}$ & $\mathrm{C}$ & $\mathrm{R}^{2}$ \\
\hline \multirow{5}{*}{$\begin{array}{l}\text { Methylene } \\
\text { Blue }\end{array}$} & 20 & 32.07 & 0.857 & 0.037 & 0.668 & 31.34 & 0.156 & 1.000 & 0.114 & 30.24 & 0.976 \\
\hline & 25 & 39.92 & 1.525 & 0.023 & 0.932 & 39.52 & 0.131 & 1.000 & 0.176 & 38.18 & 0.940 \\
\hline & 30 & 47.72 & 1.795 & 0.074 & 0.403 & 47.85 & 0.109 & 1.000 & 0.306 & 45.66 & 0.794 \\
\hline & 35 & 54.05 & 4.863 & 0.052 & 0.977 & 54.35 & 0.034 & 0.999 & 0.655 & 49.22 & 0.956 \\
\hline & 40 & 58.45 & 8.707 & 0.061 & 0.783 & 58.82 & 0.022 & 0.999 & 0.927 & 51.51 & 0.971 \\
\hline \multirow{5}{*}{ Safranin } & 20 & 30.89 & 0.872 & 0.077 & 0.552 & 30.95 & 0.200 & 1.000 & 0.255 & 29.21 & 0.526 \\
\hline & 25 & 37.17 & 2.779 & 0.034 & 0.393 & 37.87 & 0.035 & 0.999 & 0.802 & 31.45 & 0.865 \\
\hline & 30 & 38.75 & 6.039 & 0.071 & 0.833 & 39.21 & 0.031 & 0.999 & 0.912 & 32.54 & 0.833 \\
\hline & 35 & 39.72 & 7.445 & 0.067 & 0.691 & 40.32 & 0.024 & 0.999 & 0.903 & 33.27 & 0.955 \\
\hline & 40 & 43.28 & 3.733 & 0.041 & 0.768 & 43.86 & 0.030 & 0.999 & 0.707 & 38.34 & 0.956 \\
\hline
\end{tabular}
respectively, this amounts to increasing competition on the adsorbent active sites.

Table 4. Parameters of the kinetic models for methylene blue and safranin adsorption by NSC.

3.8. Thermodynamic study.

The thermodynamic parameters involved are: the Gibbs free energy $\left(\Delta \mathrm{G}^{0}\right)$, enthalpy $\left(\Delta \mathrm{H}^{0}\right)$, and entropy $\left(\Delta \mathrm{S}^{0}\right)$ were calculated using the following equation: 


$$
\begin{aligned}
& \Delta \mathrm{G}^{0}=\Delta \mathrm{H}^{0}-\mathrm{T} \Delta \mathrm{S}^{0} \\
& \ln \left(\mathrm{K}_{\mathrm{C}}\right)=\frac{\Delta \mathrm{S}^{0}}{\mathrm{R}}-\frac{\Delta \mathrm{S}^{0}}{\mathrm{RT}}
\end{aligned}
$$

Where $\mathrm{K}_{\mathrm{C}}(\mathrm{L} / \mathrm{mg}), \mathrm{R}(\mathrm{J} / \mathrm{mol} . \mathrm{K})$, and $\mathrm{T}(\mathrm{K})$ are the equilibrium constant of the adsorption process, gas constant, and absolute temperature, respectively.

The values $\Delta \mathrm{G}^{0}$ were calculated using Gibbs Equation. The values $\Delta \mathrm{H}^{0}$ and $\Delta \mathrm{S}^{0}$ can be obtained respectively from the slope and intercept of Van't Hoff plot of Ln Kc versus 1/T. Table 5 summarized the thermodynamic parameters for the adsorption of MB and SAF dyes onto NSC adsorbent. The $\Delta \mathrm{H}^{0}$ values obtained are -10.625 and $-12.641 \mathrm{in} \mathrm{kJ} / \mathrm{mol}$ for $\mathrm{MB}$ and $\mathrm{SAF}$, respectively. The negative sign indicates that the process is exothermic $[29,30]$. The increased values of $\Delta \mathrm{G}^{0}$ between $(-7.883 \mathrm{~kJ} / \mathrm{mol})$ and $(-7.607 \mathrm{~kJ} / \mathrm{mol})$ for $\mathrm{MB}$ adsorption onto NSC adsorbent and between $(-7.813 \mathrm{~kJ} / \mathrm{mol})$ and $(-7.327 \mathrm{~kJ} / \mathrm{mol})$ for SAF adsorption onto NSC with the increasing temperature $(298 \mathrm{~K}$ to $328 \mathrm{~K}$ ) indicated a decrease in the feasibility of adsorption at high temperatures. The values of entropy $\Delta \mathrm{S}^{0}$ for $\mathrm{MB}$ and $\mathrm{SAF}$ adsorption onto NSC adsorbent were (-9.2 J/mol.K) and (-16.2 J/mol.K), respectively. The negative $\Delta \mathrm{S}^{0}$ value indicates a decrease in randomness at the solid/solution interface. No significant changes occur in the adsorbent's internal structure through the adsorption. Values of $\Delta \mathrm{G}^{0}$ obtained are lower than $20 \mathrm{~kJ} / \mathrm{mol}$; this further supports the fact that the adsorption process follows the physisorption mechanism. This confirms the results following the study of the influence of $\mathrm{pH}$.

Table 5. Thermodynamic parameters for the adsorption of methylene blue and safranin on the natural Safiot

\begin{tabular}{|c|c|c|c|c|}
\hline \multicolumn{5}{|c|}{ Thermodynamic parameters } \\
\hline Adsorbate dyes & Temperature (k) & $\Delta G^{0}(\mathrm{kj} / \mathrm{mol})$ & $\Delta H^{0}(\mathrm{kj} / \mathrm{mol})$ & $\Delta \mathrm{S}^{\mathbf{0}}(\mathrm{J} / \mathrm{k} \mathrm{mol})$ \\
\hline & 298 & -7.883 & & \\
\hline \multirow[t]{4}{*}{ methylene blue } & 308 & -7.791 & -10.625 & -9.2 \\
\hline & 318 & -7.699 & & \\
\hline & 328 & -7.607 & & \\
\hline & 298 & -7.813 & & \\
\hline \multirow[t]{3}{*}{ safranin } & 308 & -7.651 & -12.641 & -16.2 \\
\hline & 318 & -7.489 & & \\
\hline & 328 & -7.327 & & \\
\hline
\end{tabular}
clay at different temperatures.

\subsection{Comparison of natural safi clay with other adsorbents.}

Table 6 summarizes the comparison of the adsorption capacity of NSC adsorbents with that reported for other adsorbents. It can be seen from Table 6 that the NSC adsorbent show a comparable adsorption capacity with respect to other adsorbents, revealing that the NSC is suitable for the removal of MB and SAF from aqueous solutions since it has a relatively high adsorption capacity.

Table 6. Comparison of the maximum monolayer adsorption capacity of the NSC for methylene blue and

\begin{tabular}{|c|c|c|c|}
\hline Dye & Adsorbent & $q_{m}\left(\mathrm{mg} \mathrm{g}^{-1}\right)$ & References \\
\hline \multirow[t]{6}{*}{ methylene blue } & natural saudi red clay & 50.25 & {$[31]$} \\
\hline & brown clay & 123.5 & [32] \\
\hline & krobo green clay & 33.90 & [33] \\
\hline & natural zeolite & 0.204 & {$[34]$} \\
\hline & zeolite & 53.10 & [35] \\
\hline & natural safiot clay & 68.49 & This study \\
\hline \multirow[t]{4}{*}{ safranin } & activated carbon (sewage-sludge) & 11.05 & {$[36]$} \\
\hline & sugar beet pulp & 147 & [37] \\
\hline & calcined mussel shells & 196.67 & {$[38]$} \\
\hline & calcined bones & 107.76 & [39] \\
\hline
\end{tabular}
safranine removal with the other adsorbents. 


\begin{tabular}{|l|l|l} 
kaolinite clay & 16.23 & {$[40]$} \\
\hline natural safiot clay & 45.45 & This study
\end{tabular}

\section{Conclusions}

In this study, the results indicated that natural safiot clay was considered low cost, ecofriendly, and a promising alternative adsorbent for removing MB and Safranin from an aqueous solution. The effect of adsorbent dose, initial concentration, contact time, temperature, and $\mathrm{pH}$ were experimentally studied to evaluate NSC's adsorption capacity; the maximum percentage removal was observed at high $\mathrm{pH}$ (basic medium) and ambient temperature. Equilibrium data fitted very well with the Langmuir isotherm equation. The kinetics of the adsorption process was found to follow the pseudo-second-order kinetic model. Therefore, the values obtained from thermodynamic parameters demonstrated that the adsorption process is exothermic, spontaneous, and physical.

\section{Funding}

This research received no external funding.

\section{Acknowledgments}

The authors are grateful who have participated in this research work.

\section{Conflicts of Interest}

The authors declare no conflict of interest.

\section{References}

1. Anuar, F.I.; Hadibarata, T.; Syafrudin, M.; Fona, Z. Removal of Procion Red MX- 5B from aqueous solution by adsorption on Parkia speciosa (stink bean) peel powder. Biointerface Res. Appl. Chem. 2020, 10, 47744779, https://doi.org/10.33263/BRIAC101.774779.

2. Katheresan, V.; Kansedo, J.; Lau, S.Y. Efficiency of various recent wastewater dye removal methods: A review. J. Environ. Chem. Eng. 2018, 6, 4676-4697, https://doi.org/10.1016/j.jece.2018.06.060.

3. Slimani, R.; El Ouahabi, I.; Abidi, F.; El Haddad, M.; Regti, A.; Laamari, M.R.; Lazar, S. Calcined eggshells as a new biosorbent to remove basic dye from aqueous solutions: thermodynamics, kinetics, isotherms and error analysis. J. Taiwan. Inst. Chem. Eng. 2014, 45, 1578-1587, https://doi.org/10.1016/j.jtice.2013.10.009.

4. El Kassimi, A.; Achour, Y.; El Himri, M.; Laamari, M. R.; El Haddad, M. Optimization of preparation conditions of highly efficient activated carbon for use in water treatment-experimental design approach. Int. J. Environ. Anal. Chem, 2021, 1-23, https://doi.org/10.1080/03067319.2020.1861261.

5. El Haddad, M.; Mamouni, R.; Saffaj, N.; Lazar, S. Evaluation of performance of animal bone meal as a new low cost adsorbent for the removal of a cationic dye Rhodamine B from aqueous solutions. J. Saudi Chem. Soc. 2016, 20, S53-S59, https://doi.org/10.1016/j.jscs.2012.08.005.

6. Regti, A.; El Ayouchia, H. B.; Laamari, M. R.; Stiriba, S. E.; Anane, H.; El Haddad, M. Experimental and theoretical study using DFT method for the competitive adsorption of two cationic dyes from wastewaters. Appl. Surf. Sci. 2016, 390, 311-319, https://doi.org/10.1016/j.apsusc.2016.08.059.

7. Somsesta, N.; Sricharoenchaikul, V.; Aht-Ong, D. Adsorption removal of methylene blue onto activated carbon/cellulose biocomposite films: Equilibrium and kinetic studies. Mater. Chem. Phys. 2020, 240, https://doi.org/10.1016/j.matchemphys.2019.122221.

8. Kristanti, R.A.; Hadibarata, T.; Al Qahtani, H.M.S. Adsorption of bisphenol A on oil palm biomass activated carbon: characterization, isotherm, kinetic and thermodynamic studies. Biointerface Res. Appl. Chem. 2019, 9, 4217-4224, https://doi.org/10.33263/BRIAC95.217224.

9. Sözüdoğru, O.; Fil, B. A.; Boncukcuoğlu, R.; Aladağ, E.; Kul, S. Adsorptive removal of cationic (BY2) dye from aqueous solutions onto Turkish clay: Isotherm, kinetic, and thermodynamic analysis. Particul. Sci. Technol. 2016, 34, 103-111, https://doi.org/10.1080/02726351.2015.1052121. 
10. Mukherjee, K.; Kedia, A.; Rao, K.J.; Dhir, S.; Paria, S. Adsorption enhancement of methylene blue dye at kaolinite clay-water interface influenced by electrolyte solutions. RSC Advances 2015, 5, 30654-30659, https://doi.org/10.1039/C5RA03534A.

11. Turabik, M. Adsorption of basic dyes from single and binary component systems onto bentonite: Simultaneous analysis of Basic Red 46 and Basic Yellow 28 by first order derivative spectrophotometric analysis method. J. Hazard. Mater. 2008, 158, 52-64, https://doi.org/10.1016/j.jhazmat.2008.01.033.

12. Lee, Y.C.; Kim, J.Y.; Shin, H.J. Removal of malachite green (MG) from aqueous solutions by adsorption, precipitation and alkaline fading using talc. Sep. Sci. Technol. 2013, 48, 1093-1101, https://doi.org/10.1080/01496395.2012.723100.

13. Hmamouchi, S.; Mesrar, L.; Eloutassi, N.; Jabrane, R. Study of the mineralogical and mechanical evolution of the miocene marls in the region of fez (morocco) during firing. Journal of Applied Sciences and Environmental Studies. 2019, 2, https://doi.org/10.48393/IMIST.PRSM/jases-v2i2.17058.

14. Shao, D.; Xu, D.; Wang, S.; Fang, Q.; Wu, W.; Dong, Y.; Wang, X. Modeling of radionickel sorption on MX-80 bentonite as a function of $\mathrm{pH}$ and ionic strength. Sci. China, Ser. B: Chem. 2009, 52, 362-371, https://doi.org/10.1007/s11426-008-0145-x.

15. Tsai, W.T.; Chen, H.P.; Hsieh, M.F.; Sun, H.F.; Chien, S.F. Regeneration of spent bleaching earth by pyrolysis in a rotary furnace. Journal of Analytical and Applied Pyrolysis 2002, 63, 157-170, https://doi.org/10.1016/S0165-2370(01)00150-4.

16. Cótica, L.F.; Freitas, V.F.; Santos, I.A.; Barabach, M.; Anaissi, F.J.; Miyahara, R.Y.; Sarvezuk, P.W.C. Cobalt-modified Brazilian bentonites: Preparation, characterisation, and thermal stability. Appl. Clay Sci., 2011, 51, 187-191, https://doi.org/10.1016/j.clay.2010.10.033.

17. Alexander, J.A.; Ahmad Zaini, M.A.; Abdulsalam, S.; El-Nafaty, U.A.; Aroke, U.O Physicochemical characteristics of surface modified Dijah-Monkin bentonite. Particul. Sci. Technol. 2018, 36, 287-297, https://doi.org/10.1080/02726351.2016.1245689.

18. Kuang, Y.; Zhang, X.; Zhou, S. Adsorption of Methylene Blue in water onto activated carbon by surfactant modification. Water 2020, 12, http://dx.doi.org/10.3390/w12020587.

19. Hee-Jeong, C.; Sung-When, Y. Biosorption of methylene blue from aqueous solution by agricultural bioadsorbent corncob. Environ. Eng. Res. 2019, 24, 99-106, https://doi.org/10.4491/eer.2018.107.

20. Kousha, M.; Daneshvar, E.; Sohrabi, M.S.; Jokar, M.; Bhatnagar, A. Adsorption of acid orange II dye by raw and chemically modified brown macroalga Stoechospermum marginatum. Chem. Eng. J. 2012, 192, 6776, https://doi.org/10.1016/j.cej.2012.03.057.

21. Jasińska, A.; Bernat, P.; Paraszkiewicz, K. Malachite green removal from aqueous solution using the system rapeseed press cake and fungus Myrothecium roridum. Desalin. Water Treat. 2013, 51, 7663-7671, https://doi.org/10.1080/19443994.2013.779939

22. Singh, N.B.; Nagpal, G.; Agrawal, S.; Rachna. Water purification by using Adsorbents: A Review. Environ. Technol. Innov. 2018, 11, 187-240, https://doi.org/10.1016/j.eti.2018.05.006.

23. Weber, T.W.; Chakravorti, R.K. Pore and solid diffusion models for fixed-bed adsorbers. AIChE Journal 1974, 20, 228-238, https://doi.org/10.1002/aic.690200204.

24. Satlaoui, Y.; Nasraoui, R.; Charef, A.; Azouzi, R. Adsorption, Modeling, Thermodynamic, and Kinetic Studies of Methyl Red Removal from Textile-Polluted Water Using Natural and Purified Organic Matter Rich Clays as Low-Cost Adsorbent. J. Chem. 2020, 2020, https://doi.org/10.1155/2020/4376173.

25. Nadir, I.; Achour, Y.; El Kassimi, A.; El Himri, M.; Laamari, M.R.; El Haddad, M. Removal of Antibiotic Sulfamethazine from Aqueous Media. Phys. Chem. Res. 2020, 9, 165-180, https://doi.org/10.22036/pcr.2020.249992.1839.

26. Aziz, E. K.; Abdelmajid, R.; Rachid, L. M.; Mohammadine, E.H. Adsorptive removal of anionic dye from aqueous solutions using powdered and calcined vegetables wastes as low-cost adsorbent. Arab. J. Basic Appl. Sci. 2018, 25, 93-102, https://doi.org/10.1080/25765299.2018.1517861.

27. Abd-Elhamid, A.I.; Emran, M.; El-Sadek, M.H.; El-Shanshory, A.A.; Soliman, H.M.A.; Akl, M.A.; Rashad, M. Enhanced removal of cationic dye by eco-friendly activated biochar derived from rice straw. Applied Water Science 2020, 10, 1-11, https://doi.org/10.1007/s13201-019-1128-0.

28. Harrou, A.; Gharibi, E.; Nasri, H.; El Ouahabi, M. Thermodynamics and kinetics of the removal of methylene blue from aqueous solution by raw kaolin. SN Applied Sciences 2020, 2, https://doi.org/10.1007/s42452020-2067-y.

29. Bello, O.S.; Ahmad, M.A.; Ahmad, N. Adsorptive features of banana (Musa paradisiaca) stalk-based activated carbon for malachite green dye removal. Chem Ecol 2012, 28, 153-167, http://dx.doi.org/10.1080/02757540.2011.628318.

30. Bello, O.S.; Fatona, T.A.; Falaye, F.S.; Osuolale, O.M.; Njoku, V.O. Adsorption of eosin dye from aqueous solution using groundnut hull-based activated carbon: kinetic, equilibrium, and thermodynamic studies. Environ. Eng. Sci. 2012, 29, 186-194, https://doi.org/10.1089/ees.2010.0385.

31. Khan, M. Adsorption of methylene blue onto natural Saudi Red Clay: isotherms, kinetics and thermodynamic studies. Mater. Res. Express. 2020, 7, https://doi.org/10.1088/2053-1591/ab903c. 
32. Munir, M.; Nazar, M.F.; Zafar, M.N.; Zubair, M.; Ashfaq, M.; Hosseini-Bandegharaei, A.; Ahmad, A. Effective Adsorptive Removal of Methylene Blue from Water by Didodecyldimethylammonium BromideModified Brown Clay. ACS omega 2020, 5, 16711-16721, https://doi.org/10.1021/acsomega.0c01613.

33. Nyankson, E.; Mensah, R.Q.; Kumafle, L.; Gblerkpor, W.N.; Aboagye, S.O.; Asimeng, B.O.; Tiburu, E.K. Dual application of natural clay material for decolorization and adsorption of methylene blue dye. Cogent Eng. 2020, 6, https://doi.org/10.1080/23312009.2020.1788291.

34. Turp, S.M.; Turp, G.A.; Ekinci, N.; Özdemir, S. Enhanced adsorption of methylene blue from textile wastewater by using natural and artificial zeolite. Water Sci. Technol. 2020, 82, 513-523, https://doi.org/10.2166/wst.2020.358.

35. Doğan, M.; Alkan, M.; Onganer, Y. Adsorption of methylene blue from aqueous solution onto perlite. Water Air Soil Pollut. 2000, 120, 229-248, https://doi.org/10.1023/A:1005297724304.

36. Rozada, F.; Calvo, L.F.; Garcia, A.I.; Martın-Villacorta, J.; Otero, M. Dye adsorption by sewage sludgebased activated carbons in batch and fixed-bed systems. Bioresour. Technol. 2003, 87, 221-230, https://doi.org/10.1016/S0960-8524(02)00243-2.

37. Malekbala, M.R.; Hosseini, S.; Yazdi, S.K.; Soltani, S.M.; Malekbala, M.R. The study of the potential capability of sugar beet pulp on the removal efficiency of two cationic dyes. Chem. Eng. Res. Des. 2012, 90, 704-712, https://doi.org/10.1016/j.cherd.2011.09.010.

38. El Haddad, M.; Regti, A.; Slimani, R.; Lazar, S. Assessment of the biosorption kinetic and thermodynamic for the removal of safranin dye from aqueous solutions using calcined mussel shells. J. Ind. Eng. Chem, 2014, 20, 717-724, https://doi.org/10.1016/j.jiec.2013.05.038.

39. El Haddad, M.; Slimani, R.; Mamouni, R.; Laamari, M.R.; Rafqah, S.; Lazar, S. Evaluation of potential capability of calcined bones on the biosorption removal efficiency of safranin as cationic dye from aqueous solutions. J. Taiwan. Inst. Chem. Eng. 2013, 44, 13-18, https://doi.org/10.1016/j.jtice.2012.10.003.

40. Adebowale, K.O.; Olu-Owolabi, B.I.; Chigbundu, E.C. Removal of safranin-O from aqueous solution by adsorption onto kaolinite clay. J.E.A.S, 2014, 4, https://doi.org/10.4236/jeas.2014.43010. 